\title{
VTIQ evaluates antitumor effects of NET-1 siRNA by UTMD in HCC xenograft models
}

\author{
XITIAN LIANG, BOLIN WU, HAITAO SHANG, XUE HAN, HUI JING, YIXIN SUN and WEN CHENG \\ Department of Ultrasonography, Harbin Medical University Cancer Hospital, \\ Nangang, Harbin, Heilongjiang 150000, P.R. China
}

Received November 20, 2017; Accepted April 27, 2018

DOI: $10.3892 / \mathrm{ol} .2018 .8994$

\begin{abstract}
The present study used a virtual touch tissue imaging and quantification (VTIQ) method to investigate the change in elasticity in xenograft tumor tissue models following silencing of the neuroepithelial-transforming protein 1 (NET-1) gene by ultrasound-targeted microbubble destruction (UTMD). A total of 24 xenograft models were established by subcutaneous injection of human hepatocellular carcinoma SMMC-7721 cells in BALB/c female nude mice. Then, NET-1 small interfering RNA (siRNA)-conjugated nanobubbles and a glypican-3 antibody were synthesized. The mean and maximum shear wave speed $\left(\mathrm{SWS}_{\text {mean }}\right.$ and $\mathrm{SWS}_{\max }$ ) in the tumor tissue were measured prior to, during, and following therapy using VTIQ. The growth of the tumor size and survival time were recorded. The levels of NET-1 protein were evaluated by immunohistochemical staining. In addition, tumor, liver and kidney tissues of the nude mice were collected to confirm whether gene transfection treatment was toxic in vivo. In the UTMD delivery gene group, $\mathrm{SWS}_{\text {mean }}$ was correlated with the maximum diameter of the tumor $(r=0.9806, P=0.0194)$. The immunohistochemical staining data indicated that the level of NET-1 protein in the treated groups was significantly decreased compared with those in the control groups. Additionally, no structural damage was observed in the nude mice liver and kidney tissues following treatment. Therefore, VTIQ measurement identified potential changes in the elastic properties of the tumors, which in turn may be associated with the stages of tumor development. The delivery method, UTMD, improves the antitumor effects of NET-1 siRNA and supports gene transfection as a promising therapeutic strategy.
\end{abstract}

Correspondence to: Dr Wen Cheng, Department of Ultrasonography, Harbin Medical University Cancer Hospital, 150 Haping Road, Nangang, Harbin, Heilongjiang 150000, P.R. China

E-mail: chengwen69@yahoo.com

Key words: hepatocellular carcinoma, virtual touch tissue imaging and quantification, neuroepithelial-transforming protein 1 small interfering RNA, ultrasound-targeted microbubble destruction

\section{Introduction}

A variety of elastography techniques have been developed to visualize and quantify the mechanical properties of biological tissues, including thyroid, breast and liver tissues $(1,2)$. In previous years, virtual touch tissue imaging and quantification (VTIQ), a novel two-dimensional shear wave speed (SWS) measurement technique, has been introduced into clinical practice, which not only provides qualitative but also quantitative measurements of the tissue stiffness (3-5). VTIQ is based on the acoustic radiation force imaging method, which transmits ultrasonic pulses in the targeted tissue, resulting in a tissue displacement of 1-20 $\mu \mathrm{m}$, thereby attenuating the tissues to establish elasticity (6). Elasticity is a biological and mechanical property, which represents the stiffness of the tumor tissue (7). This characteristic may be associated with the physiological or pathological processes of the tissue structure (8). Therefore, the evaluation of elasticity in tumor-bearing mice may be a tool to monitor the development of hepatocellular carcinoma (HCC) and putatively detect the physiological and pathological variation in the tissues during liver carcinogenesis.

$\mathrm{HCC}$, a major type of primary liver cancer, is one of the most prevalent human malignancies globally (9). In a number of cases, the disease may remain undiagnosed until patients reach terminal-stage disease, and are therefore not eligible for curative surgical resection (10). In addition, HCC has a high recurrence rate, frequent metastasis events and several postoperative complications post-surgery (11). Therefore, identification of novel biomarkers for its early diagnosis and specific targets for therapy is essential. At present, liver carcinogenesis is considered to be stimulated by the accumulation of various genetic and epigenetic alterations (12). Compared with conventional treatment methods, including chemotherapy and surgery, gene therapy may kill tumor cells accurately and efficiently with fewer side effects $(13,14)$.

RNA interference (RNAi) is an effective tool for inhibiting gene expression. It may silence the expression of targeted genes by binding to specific mRNA and triggering their degradation (15). This selective knockdown of specific gene sequences supports RNAi as a promising therapeutic strategy. Neuroepithelial cell-transforming gene 1 (NET-1) protein is characterized by the presence of 4 hydrophobic domains and belongs to the tetraspanin superfamily (TM4SF) (16). It has been demonstrated that the NET- 1 gene is involved in the division, 
proliferation and carcinogenesis of HCC cells (17-19). The level of NET-1 expression exhibits a significant association with HCC pathological grading and clinical stages $(20,21)$. Therefore, the present study selected the NET-1 gene sequence as a rational target for HCC therapy $(22,23)$. Glypican-3 (GPC3) is one of the glypican families of heparin sulfate proteoglycans, and is highly expressed on the surface of HCC cells but not in normal tissue $(24,25)$. Therefore, GPC3 may be a promising biomarker for initial diagnosis, immunological therapy and assessing the risk of HCC recurrence (26-28). Furthermore, compared with Lipofectamine ${ }^{\circledast} 2000$ (Lipo2000), ultrasound-targeted microbubble destruction (UTMD) may enhance gene permeability and retention effect (29). It is reported that the nanobubbles with 30-200 $\mathrm{nm}$ in hydrodynamic diameter accumulate with high efficiency in many solid tumors by EPR effect (30). At present, several studies have utilized a nanobubbles-mediated targeted RNAi delivery system as a novel therapeutic method for the treatment of HCC (31-33). The UTMD delivery method has a number of advantages, including low cytotoxicity, low immunogenicity and dual role of ultrasound imaging and ultrasound-mediated therapy (34).

In the present study, we hypothesized that the UTMD delivery system may increase the efficacy of gene transfection, and VTIQ was used to measure the changes in elasticity in the tumor tissues that received NET-1 small interfering (si)RNA treatment.

\section{Materials and methods}

Xenograft model. All animal experiments were approved by the Institutional Animal Care and Use Committee of Harbin Medical University Cancer Hospital (Harbin, China). Surgical procedures were performed under isoflurane anesthesia inhalation (1-2\% in 100\% oxygen; RWD Life Science Co., Ltd. Shenzhen, China).

A total of 30 female BALB/c nude mice with a mean weight of $19.3 \mathrm{~g}, 5-6$-weeks-old, purchased from Beijing Vital River Laboratory Animal Technology Co., Ltd. (Beijing, China), were housed in individually ventilated cages with sawdust on a 12-h day/night cycle under specific pathogen-free conditions and room temperature for 1 week prior to experiments. During the experiment, the nude mice were allowed ad libitum access to food and water. SMMC-7721 cells $\left(2 \times 10^{6}\right)$, were gifted from the Institute of Cancer Research affiliated to Harbin Medical University (Harbin, China), were suspended in $100 \mu 1 \mathrm{PBS}$ and injected subcutaneously into the lower back of the mice. The maximum diameter of the tumor was representative of tumor growth and was measured twice/week using Vernier calipers. The experimental procedures were conducted in the xenograft models when the tumor diameters reached $>5 \mathrm{~mm}$. However, the tumor only reached the pre-determined experimental size in 24 mice. When the maximum diameter of the tumor reached $\sim 20 \mathrm{~mm}$, or at 60 days following the first injection, the animals were sacrificed following the institutional ethical guidelines.

Preparation and characterization of NET-1 small interfering RNA (siRNA)-conjugated targeted nanobubbles. The NET-1 siRNA was conjugated with biotin; the compound was synthesized by Shanghai GenePharma Co., Ltd. (Shanghai, China). The BLAST analysis (http://www.ncbi.nlm.nih.gov/blast/)
Table I. Sequences of NET-1 and negative control siRNA.

\begin{tabular}{ll}
\hline Gene & \multicolumn{1}{c}{ Sequences } \\
\hline NET-1 siRNA & Sense:5'-GGGCAUCCUUUCUGA \\
& AGAUTT-3' \\
& Antisense: 5'-AUCUUCAGAAAG \\
& GAUGCCCTT-3' \\
& Sense:5'-UUCUCCGAACGUGUC \\
Negative control & ACGUTT-3' \\
& Antisense: 5'-ACGUGACACGUU \\
& GGGAGAATT-3' \\
\end{tabular}

NET-1, Neuroepithelial cell-transforming gene 1 protein; siRNA, small interfering RNA.

ensured that the siRNA specifically binds the targeted gene (accessed 6 September 2017). According to the manufacturer's recommendations, the NET-1 siRNA was covalently labeled with Cy3 using the Label IT kit (Mirus Bio, LLC Madison, WI, USA). The sequences of NET-1 siRNA and negative control are described in Table I.

Based on our previous study (35), 1,2-Distearoyl-sn-glycero3-phosphocholine, 1,2-Distearoyl-sn-glycero-3-phospho ethanolamine (DSPE) and DSPE-PEG2000-biotin were utilized at a 9:0.5:0.5 molar ratio to formulate the lipid nanobubbles. Firstly, the mixture was solubilized in $99.7 \%$ chloroform, which was subsequently evaporated for $5 \mathrm{~min}$ by vacuum rotary evaporation at $1,000 \mathrm{xg}$ at $37^{\circ} \mathrm{C}$. This resulted in the formation of a lipid film that was resolubilized in $5 \mathrm{ml}$ PBS for $3 \mathrm{~min}$ at $40^{\circ} \mathrm{C}$. Next, the air was exhausted from the sealed vials using a syringe, and $99.90 \%$ perfluoropropane (Research Institute of Physical and Chemical Engineering of Nuclear Industry, Tianjin, China) was added. Then, the mixture was mechanically vibrated for $45 \mathrm{sec}$ in a dental amalgamator with $50 \mathrm{~Hz}$ at $37^{\circ} \mathrm{C}$ (Hubei YJT Technology Co., Ltd., Shanghai, China), and the resulting solution was sonicated with a $20 \mathrm{kHz}$ probe (Sonics \& Materials, Inc., Newtown, CT, USA). Finally, the nanoparticles were washed with sterile PBS and centrifuged at $800 \mathrm{xg}$ for $5 \mathrm{~min}$ at $37^{\circ} \mathrm{C}$. The biotinylated GPC3 (ab218874; 1:1,000; Abcam, Cambridge, MA, USA) antibody, NET-1 siRNA and nanobubbles were gently agitated in PBS, and the mixture was incubated at $4^{\circ} \mathrm{C}$ overnight to form the NET-1 siRNA-TNBs (targeted nanobubbles) complexes.

The particle size was measured using a Zetasizer Nano ZS90 analyzer (Malvern Instruments Ltd., Malvern, UK). The NET-1 siRNA conjugated with TNBs was detected by confocal laser scanning microscopy (x200, magnification) (Olympus Corporation, Tokyo, Japan).

Gene transfection. As summarized in Table II, 24 xenograft mice were randomized into four groups. The timeline of the experiment is demonstrated in Fig. 1. For every group (A-D), the experimental injection was administered 4 times (days 1, 5, 9 and 13). For group D, the NET-1 siRNA-conjugated TNBs $(100 \mathrm{mg} / \mathrm{kg})$ were injected into BALB/c nude mice via the tail vein. For group C, Lipo2000 (Invitrogen; Thermo Fisher 
Table II. Experimental groups and corresponding treatments.

\begin{tabular}{lll}
\hline Group & \multicolumn{1}{c}{ Experimental treatment } & Abbreviations \\
\hline A & Normal saline & Blank control \\
B & Targeted nanobubbles + negative control RNA & TNBs + NC \\
C & Lipofectamine ${ }^{\circledR} 2000+$ NET-1 siRNA & Lipo2000 + siRNA \\
D & NET-1 siRNA-conjugated targeted nanobubbles & TNBs-siRNA
\end{tabular}

NET-1, Neuroepithelial cell-transforming gene 1 protein; siRNA, small interfering RNA.

Scientific, Inc., Waltham, MA, USA) was used as a control for the delivery of NET-1 siRNA into nude mice. The Lipo2000 $(100 \mathrm{mg} / \mathrm{kg}$ ) was also injected via the tail vein, according to the manufacturer's protocol. Nude mice in all groups underwent ultrasound examination, which was performed for $45 \mathrm{sec}$ with a Low-Frequency Ultrasound Transfection Instrument (Institute of Ultrasound Imaging, Second Affiliated Hospital of Chongqing Medical University, Chongqing, China) at the following settings: Frequency of $1 \mathrm{MHz}$, pulse repetition frequency of $1 \mathrm{kHz}, 50 \%$ duty cycle, and $1 \mathrm{~W} / \mathrm{cm}^{2}$ intensity.

VTIQ measurements. Ultrasound scanning was performed 4 times (days 0, 7, 14 and 21). VTIQ was performed by a radiologist (Harbin Medical University Cancer Hospital, Harbin, China) with $>2$ years of experience performing ultrasound scanning elastography with Siemens Acuson S3000 Device (Siemens Medical Solutions, Mountain View, CA, USA), which was equipped with a 9L4 linear array transducer (frequency range, 4-9 MHz). Nude mice were anesthetized and positioned on the bed. Subsequently, the transducer was placed perpendicular to the target tumor. The operator held the transducer as lightly as possible, in order to minimize the pre-compression distortion.

As demonstrated in Fig. 2, the measurement of SWS on each tumor was repeated 7 times. The $7 \mathrm{SW}$ regions of interest (SW-ROI) were placed arbitrarily on the lesions with homogeneous SW distribution. In the case of lesions with heterogeneous SW distribution, 2 SW-ROIs were placed on the highest and lowest stiffness areas, respectively, corresponding to the SW distribution on the SW-velocity map, and the other $5 \mathrm{SW}$-ROIs were placed in the remaining areas at random. Although large tumors are easy to manipulate, visualize and analyze, they often form a necrotic core (36). Cystic, calcified and necrotic areas corresponding with low or marginal quality on SW-quality map were avoided while placing the SW-ROI on the SW-velocity map, as these factors may affect the measurements (37). Using SW-ROI, the SWS may be quantitatively measured in $\mathrm{m} / \mathrm{s}$. The scale of SWS ranged from $0.5-10 \mathrm{~m} / \mathrm{s}$ and was not adjusted during the entire process. As a result, 7 values were obtained to compute the value of $\mathrm{SWS}_{\max }$ and $\mathrm{SWS}_{\text {mean }}$ for the subsequent comparisons between groups.

Histological analysis and toxicity test. When nude mice were sacrificed, all tumors were rapidly harvested, fixed in $10 \%$ formalin at room temperature for $24 \mathrm{~h}$ and embedded in paraffin using a Leica EG 1160 embedder (Leica
Microsystems GmbH, Wetzlar, Germany). Tumor tissues were cut into $4-\mu \mathrm{m}$ thick slices using a Leica CM1850 cryostat (Leica Microsystems GmbH). Tissue sections were dewaxed in xylene and re-hydrated through graded alcohol concentrations using standard procedures (anhydrous ethanol; 95, 90, 85 and $80 \% ; 10 \mathrm{~min}$ for each step) at $37^{\circ} \mathrm{C}$. After washing in PBS (thrice for $5 \mathrm{~min}$ ), peroxidase was blocked by incubation in $3 \%$ $\mathrm{H}_{2} \mathrm{O}_{2}$ (Beyotime Institute of Biotechnology, Haimen, China) for $10 \mathrm{~min}$ at room temperature. The slides were washed twice in PBS and incubated for $24 \mathrm{~h}$ with rabbit anti-human NET-1 polyclonal antibody (ab113202; 1:1,000; Abcam, Shanghai, China) diluted in $0.01 \mathrm{M}$ PBS containing $0.3 \%$ Triton X-100 and $0.5 \%$ bovine serum albumin (BSA; Boster Biological Technology, Pleasanton, CA, USA). Following incubation, sections were washed with PBS (thrice for $5 \mathrm{~min}$ ) and subsequently incubated with goat anti-rabbit monoclonal secondary antibody (ab79006; 1:100; Abcam) at $37^{\circ} \mathrm{C}$ for $30 \mathrm{~min}$. Finally, tissue slides were stained with 3,3'-diaminobenzidine (Shanghai Mingrui Biological Technology Co., Ltd., Shanghai, China) at room temperature for $5 \mathrm{~min}$ and counterstained with hematoxylin (Beyotime Institute of Biotechnology) at room temperature for $10 \mathrm{~min}$. All incubations were performed at room temperature (8).

For the toxicity assessment of NET-1 siRNA-conjugated TNBs, standard Harris hematoxylin $(5 \mathrm{mg} / \mathrm{ml})$ and eosin (10 $\mathrm{mg} / \mathrm{ml})(\mathrm{H} \& \mathrm{E})$ staining was performed on the liver and kidney samples (38). The liver and kidney tissues were immersed in $10 \%$ formalin for $24 \mathrm{~h}$. Then the slides were placed in processing cassettes, dehydrated through a serial alcohol gradient $(50,70,80,85,90$ and $95 \%$ anhydrous ethanol twice; $10 \mathrm{~min}$ for each step) at $37^{\circ} \mathrm{C}$, and embedded in paraffin wax blocks. $5-\mu \mathrm{m}$ thick live and kidney tissue sections were dewaxed in xylene, rehydrated through decreasing concentrations of ethanol (anhydrous ethanol; 95, 90, 85 and 80\%; $10 \mathrm{~min}$ for each step) at $37^{\circ} \mathrm{C}$, and washed in dilled water. The slides were then stained in hematoxylin solution for $1 \mathrm{~min}$ at $37^{\circ} \mathrm{C}$. Excessive chromatin, which was bound to the tissues, was removed from tissues with $1 \%$ hydrochloric alcohol solution for $5 \mathrm{sec}$ at room temperature. The slides were washed in dilled water for $1 \mathrm{~min}$ and stained with eosin for $30 \mathrm{sec}$ at $37^{\circ} \mathrm{C}$. Finally, the slides were dehydrated in alcohol $(80,85$, 90 and $95 \%$ anhydrous ethanol; $3 \mathrm{~min}$ for each step) at $37^{\circ} \mathrm{C}$ and mounted with Eukitt quick-hardening mounting medium (Sigma-Aldrich, Merck KGaA, Darmstadt, Germany). An experienced pathologist belonged to the department of pathology, Harbin Medical University Cancer Hospital, evaluated hepatic 


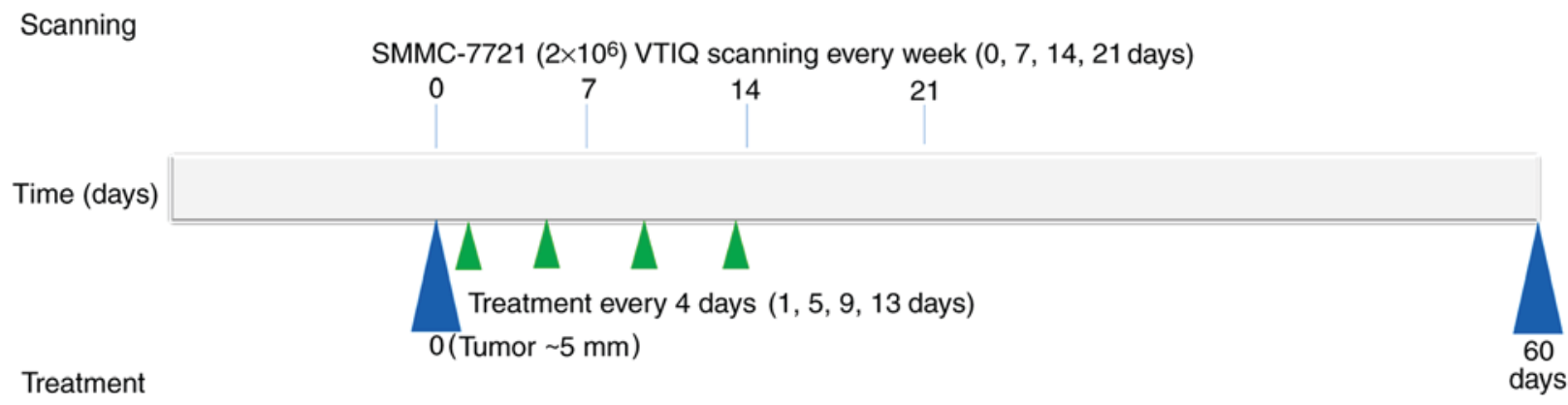

Figure 1. Schematic design of the experiment. When the xenograft models exhibited tumor diameters $>5 \mathrm{~mm}$, VTIQ measurement (day $0,7,14$ and 21 ) and treatment (day 1,5,9 and 13) were performed in the four groups. Nude mice were sacrificed when the maximum diameter of the tumor reached $\sim 20 \mathrm{~mm}$ or at 60 days following the first injection.
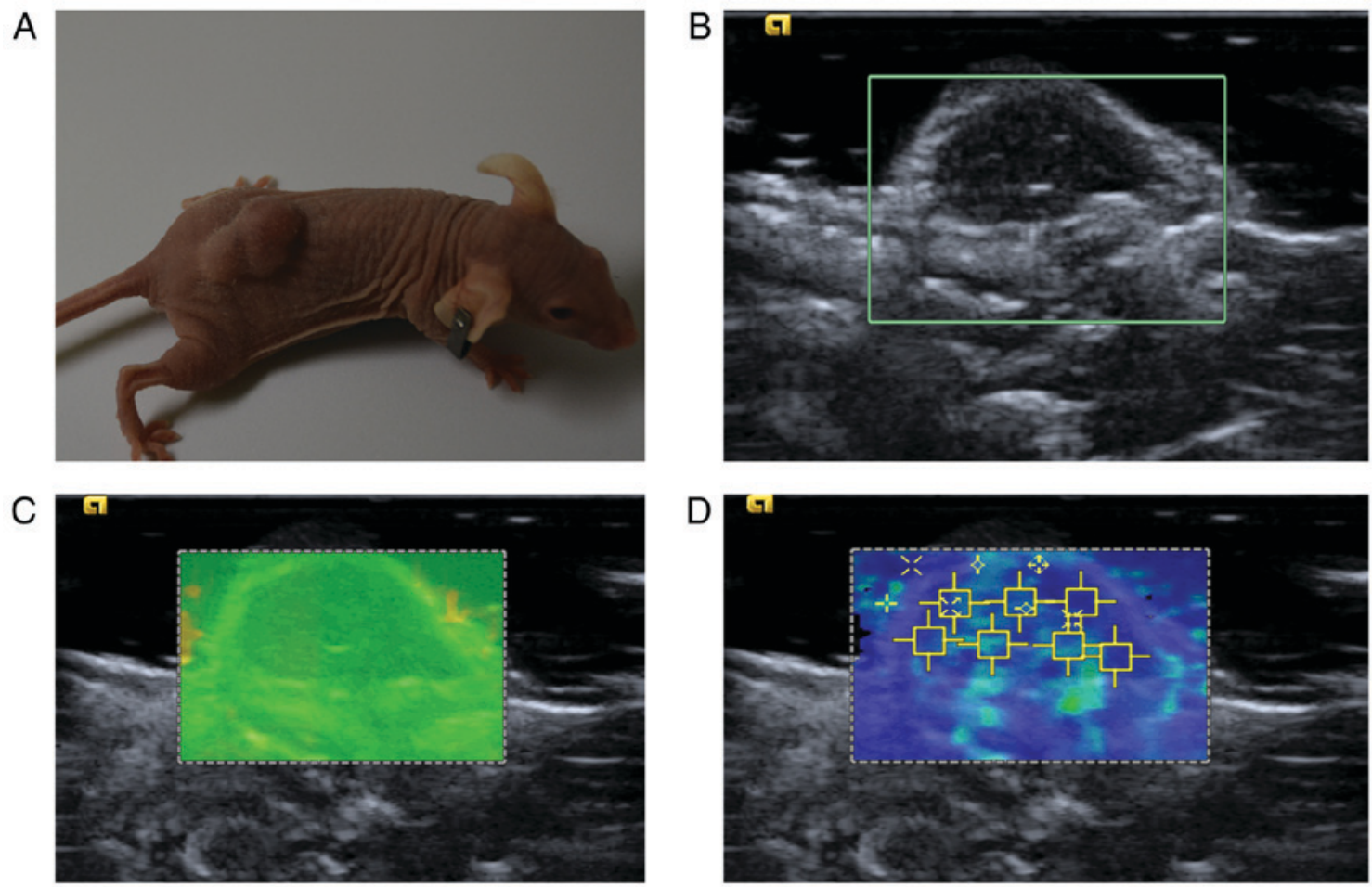

Figure 2. VTIQ images acquired from the xenograft model. (A) A nude mouse with xenograft tumor on the back. (B) The conventional ultrasound indicated that the xenograft tumor and the sampling box were adjusted to cover the target tumor tissue. (C) SW-quality map. Orange and green colors indicated low- and high-quality, respectively. (D) SW-velocity map. Different colors indicated the SWS by red for high, which did not exist in this map, blue for low, and green for intermediate. Shear wave velocity was subsequently measured by placing a small SW-region of interest square (yellow rectangular frame, $\sim 2 \times 2 \mathrm{~mm}$ ) over the map. SW, Shear wave; SWS, Shear wave speed.

and renal toxicity using a light microscope. The images of the tissue slides were obtained by montage imaging via the automated tiling function of the light microscope (magnification, $x 100)$. The quantified analysis of NET-1 protein in the tumor tissue was done using ImageJ software (1.46; National Institutes of Health, Bethesda, MD, USA) (39).

Statistical analysis. All statistical analysis were performed using GraphPad Prism 5.01 software (GraphPad Software Inc., La Jolla, CA, USA). An unpaired Student's t-test was performed. A two-way analysis of variance (ANOVA) analyzed the effect of treatment type and duration on tumors, and Bonferroni post hoc tests were used to compare the control and the treated groups at each time point. The log-rank test and Kaplan-Meier analysis were performed to assess the survival rates. Pearson's correlation coefficient was used to compare the maximum diameter of the tumor and tumor elasticity. The measurement data are expressed as mean \pm standard deviation. $\mathrm{P}<0.05$ was considered to indicate a statistically significant difference.

\section{Results}

Characterization of the TNBs-blank and siRNA-conjugated TNBs. The combination between NET-1 siRNA and TNBs was established using light microscope and confocal laser scanning microscope, as demonstrated in Fig. 3. The nanobubble surfaces appeared red under confocal laser scanning microscopy, indicating that the cy3-labeled NET-1 siRNA was 
A

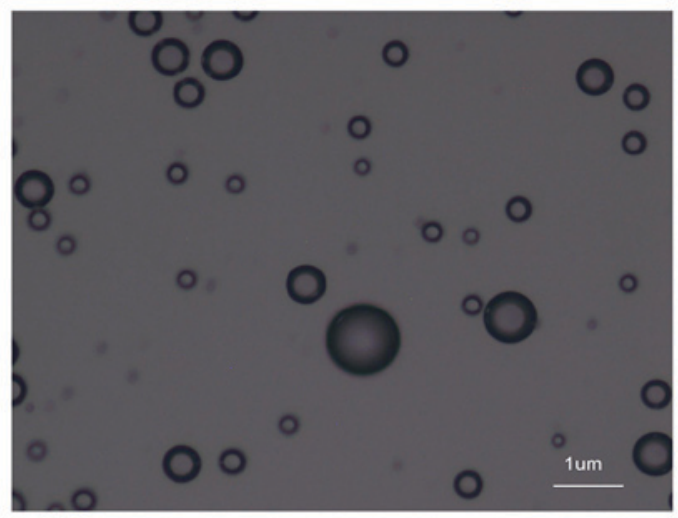

B

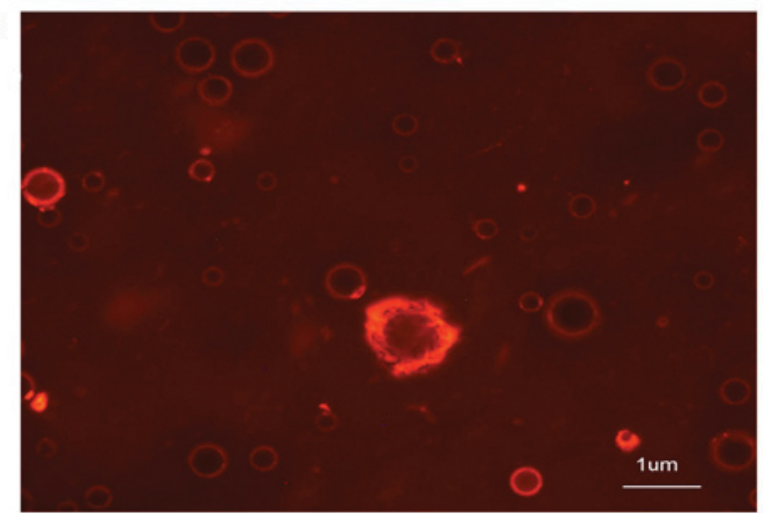

\begin{tabular}{|c|c|c|c|c|}
\hline Run & Eff. Diam. (nm) & Half width (nm) & Polydispersity & Baseline index \\
\hline 1 & 582.6 & 41.2 & 0.005 & $8.3 / 87.61 \%$ \\
\hline 2 & 516.3 & 36.5 & 0.005 & $8.9 / 91.23 \%$ \\
\hline 3 & 537.9 & 38.0 & 0.005 & $5.7 / 92.92 \%$ \\
\hline 4 & 662.2 & 266.5 & 0.162 & $2.3 / 91.15 \%$ \\
\hline 5 & 665.7 & 305.1 & 0.210 & $0.0 / 91.15 \%$ \\
\hline Mean & 539.0 & 137.5 & 0.077 & $5.0 / 90.81 \%$ \\
\hline Std. Error & 30.9 & 60.9 & 0.045 & $1.7 / 0.87$ \\
\hline Combined & 497.9 & 173.4 & 0.121 & $5.4 / 90.81 \%$ \\
\hline
\end{tabular}

Figure 3. Representative microscopic images and particle size of Cy3-labeled NET-1 siRNA-conjugated TNBs. (A) TNBs were observed under a light microscope at magnification, $\mathrm{x} 400$ (scale bar, $1 \mu \mathrm{m}$ ). (B) TNBs conjugated with Cy3-labeled NET-1 siRNA were visualized under a confocal laser scanning microscope at magnification, $\mathrm{x} 400$ (scale bar, $1 \mu \mathrm{m}$ ). (C) Analysis of the particle size and diameter. NET-1, Neuroepithelial cell-transforming gene 1 protein; TNBs, targeted nanobubbles; Eff. Diam., effective diameter.

packaged on the TNB surfaces. The concentration of nanobubbles was $3 \times 10^{8} / \mathrm{ml}$. The average diameter of the particle was $593 \pm 30.9 \mathrm{~nm}$, which is able to pass the capillary wall and reach the tumor tissue (40).

Elastic properties of tumor. Firstly, prior to treatment, no significant difference was observed in the $\mathrm{SWS}_{\max }$ or $\mathrm{SWS}_{\text {mean }}$ (day 0) among the four groups $(\mathrm{P}>0.05)$. Also, no significant difference was noted in the 4 SWS measurements, including $\mathrm{SWS}_{\max }$ and $\mathrm{SWS}_{\text {mean }}$, between the blank and negative control groups $(\mathrm{P}>0.05)$. Next, the two-way ANOVA indicated that the duration and types of treatment significantly affected the SWS values. The effect of NET-1 siRNA on tumor elasticity was evaluated by VTIQ measurement. As demonstrated in

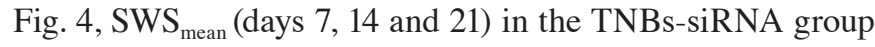
was significantly different compared with the blank group $(\mathrm{P}<0.001)$. The difference was also observed in $\mathrm{SWS}_{\max }$ at days 14 and 21. In addition, SWS $_{\text {mean }}$ (days 14 and 21) in the TNBs-siRNA group was statistically different from the Lipo2000 group $(\mathrm{P}<0.05$ and $\mathrm{P}<0.01)$. However, no significant difference was observed in the $4 \mathrm{SWS}_{\max }$ measurements between groups $\mathrm{C}$ and $\mathrm{D}(\mathrm{P}>0.05)$. The last VTIQ value (day 21) for the $\mathrm{SWS}_{\text {mean }}$ in groups $\mathrm{A}, \mathrm{B}, \mathrm{C}$ and $\mathrm{D}$ was $3.64 \pm 0.24,3.88 \pm 0.30,3.22 \pm 0.11$ and $2.81 \pm 0.20 \mathrm{~m} / \mathrm{s}$, respectively (Table III).

Pearson's correlation analysis established a significantly positive correlation $(\mathrm{r}=0.9806, \mathrm{P}=0.0194)$ between the maximum diameter of tumor and $\mathrm{SWS}_{\text {mean }}$ for group $\mathrm{D}$. However, $\mathrm{SWS}_{\max }$ was not significant $(\mathrm{r}=0.8825, \mathrm{P}=0.1175)$.

Antitumor effect. As observed in Fig. 5, the survival times and tumor growth of every group were evaluated. In the two treated groups delivering NET-1 siRNA with TNBs or Lipo2000, the survival rates were increased compared with the control groups. The median survival rates of groups A, B, $\mathrm{C}$ and $\mathrm{D}$ were 28, 35, 56 and 60 days, respectively. Although all the tumors, with or without treatment, increased in size, the tumor growth rate in group D was significantly decreased compared with that in the other groups. Silencing the NET-1 gene inhibited the tumor growth, thereby increasing the rate of survival.

Expression of NET-1 in tumor tissue and hepatic and renal toxicity. Immunohistochemical staining indicated that the level of NET-1 expression in the treated groups (C and D) was downregulated compared with the blank controls by quantified analysis. In addition, the level of NET-1 protein in the TNBs-siRNA group was significantly different from that of the Lipo2000 group $(\mathrm{P}<0.05)$. No difference was observed between the blank and negative controls (Fig. 6).

Using microscopy, tumor metastasis was identified in liver samples from groups A and B, which was not observed in groups $\mathrm{C}$ and D. No marked pathological changes were observed in kidney samples from either of the groups (Fig. 7). 

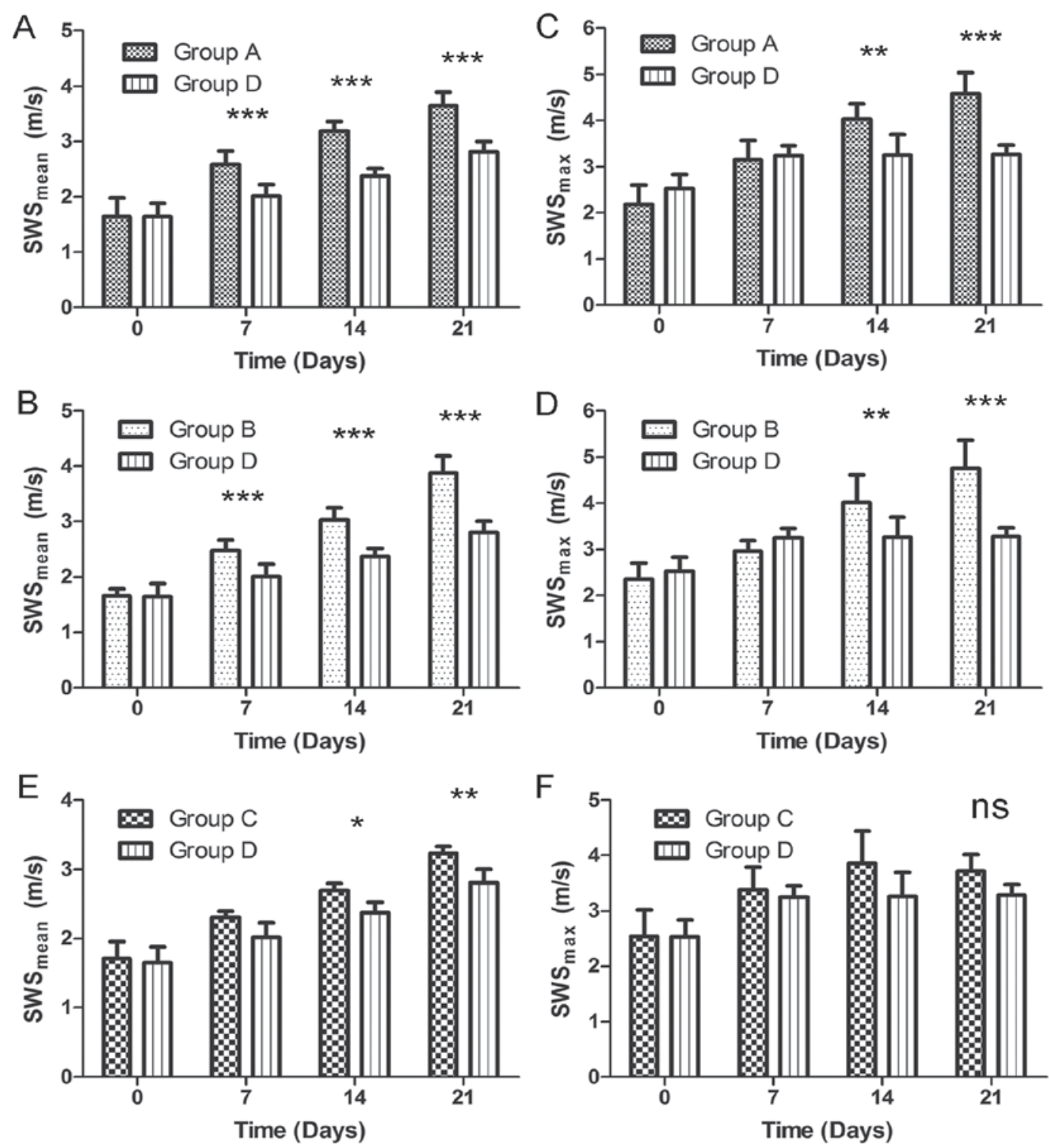

Figure 4. Comparison of $\mathrm{SWS}_{\text {mean }}$ and $\mathrm{SWS}_{\max }$ between groups. For $\mathrm{SWS}_{\text {mean }}$ measurement, the treated group D was statistically different from control groups including (A) group A and (B) group B except to before the experiment. Similarly, the significant difference in SWS $\mathrm{S}_{\max }$ (day 7 , 14 and 21 ) was also shown

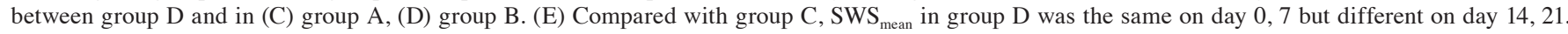
(F) There was no significant different in four time $\mathrm{SWS}_{\max }$ measurement between group C and D. Bonferroni post-hoc tests were used for comparisons at each time point after the two-way analysis of variance (ANOVA). ${ }^{*} \mathrm{P}<0.05,{ }^{* *} \mathrm{P}<0.01$ and ${ }^{* * * *} \mathrm{P}<0.001$. SWS, shear wave speed; ns, not significant.

\section{Discussion}

In the present study, the antitumor effect of gene transfection was initially evaluated using VTIQ. As a clinical diagnostic tool, VTIQ assesses the stiffness of the tissue, which aids in clinical differentiation between benign and malignant nodules (41). Previous studies have demonstrated the changes in the value of tumor stiffness during disease progression $(42,43)$. Quantitative elastography techniques, including virtual touch tissue quantification and VTIQ, provide valuable information for assessing the stiffness of the tumor tissue (44). In the present study, the VTIQ was measured once/week, based on the treatment frequency and data obtained from a previous study (45). SWS $\mathrm{S}_{\text {mean }}$ and $\mathrm{SWS}_{\max }$ values from the four groups were compared at each time point. A two-way ANOVA investigated the effect of treatment and time on SWS measurement. It was identified that VTIQ was able to track the alterations in elastic modules in response to gene therapy. SWS and stiffness in tumor tissue increased gradually with the development of the tumor. This result was consistent with that of a previous study (46). A significant difference was observed in SWS between the control and treated groups, suggesting that the rate of hardening of the tumor was decreased by gene treatment. In addition, $\mathrm{SWS}_{\text {mean }}$ in the Lipo2000 group was significantly different from that in the TNBs-siRNA group; this demonstrated the improved effect of UTMD-mediated gene transfection compared with that of Lipo2000. The $\mathrm{SWS}_{\text {mean }}$ values were markedly correlated with the tumor growth curve induced by NET-1 siRNA. However, it was also noted that comparison of the $\mathrm{SWS}_{\max }$ values between the two treated groups did not indicate a significant difference, which may be attributed to the location of the 7 ROIs that avoided 
Table III. The result of SWS measurement of the four groups. SWS $\mathrm{Sean}_{\text {and }}$ SWS $\mathrm{Sax}_{\min }$ four groups were expressed as mean $\pm \mathrm{SD}$ $(\mathrm{m} / \mathrm{s})$ and measured by virtual touch tissue imaging and quantification on days $0,7,14$ and 21 .

\begin{tabular}{|c|c|c|c|c|c|c|c|c|}
\hline \multicolumn{9}{|c|}{$\mathrm{A}, \mathrm{SWS}_{\text {mean }}$} \\
\hline \multirow[b]{2}{*}{ Day } & \multicolumn{2}{|c|}{ Group A } & \multicolumn{2}{|c|}{ Group B } & \multicolumn{2}{|c|}{ Group C } & \multicolumn{2}{|c|}{ Group D } \\
\hline & Mean \pm SD & $\mathrm{n}$ & Mean \pm SD & $\mathrm{n}$ & Mean \pm SD & $\mathrm{n}$ & Mean \pm SD & $\mathrm{n}$ \\
\hline 0 & $1.65 \pm 0.33$ & 6 & $1.66 \pm 0.12$ & 6 & $1.71 \pm 0.24$ & 6 & $1.64 \pm 0.24$ & 6 \\
\hline 7 & $2.59 \pm 0.24$ & 6 & $2.47 \pm 0.20$ & 6 & $2.30 \pm 0.10$ & 6 & $2.01 \pm 0.22$ & 6 \\
\hline 14 & $3.19 \pm 0.17$ & 5 & $3.02 \pm 0.22$ & 6 & $2.69 \pm 0.11$ & 6 & $2.37 \pm 0.15$ & 6 \\
\hline 21 & $3.64 \pm 0.24$ & 3 & $3.88 \pm 0.30$ & 3 & $3.22 \pm 0.11$ & 5 & $2.81 \pm 0.20$ & 6 \\
\hline
\end{tabular}

$\mathrm{B}, \mathrm{SWS}_{\max }$

\begin{tabular}{|c|c|c|c|c|c|c|c|c|}
\hline \multirow[b]{2}{*}{ Day } & \multicolumn{2}{|c|}{ Group A } & \multicolumn{2}{|c|}{ Group B } & \multicolumn{2}{|c|}{ Group C } & \multicolumn{2}{|c|}{ Group D } \\
\hline & Mean \pm SD & $\mathrm{n}$ & Mean \pm SD & $\mathrm{n}$ & Mean \pm SD & $\mathrm{n}$ & Mean \pm SD & $\mathrm{n}$ \\
\hline 0 & $2.18 \pm 0.42$ & 6 & $2.34 \pm 0.35$ & 6 & $2.54 \pm 0.48$ & 6 & $2.53 \pm 0.31$ & 6 \\
\hline 7 & $3.15 \pm 0.42$ & 6 & $2.95 \pm 0.24$ & 6 & $3.38 \pm 0.42$ & 6 & $3.25 \pm 0.20$ & 6 \\
\hline 14 & $4.04 \pm 0.33$ & 5 & $4.01 \pm 0.60$ & 6 & $3.85 \pm 0.59$ & 6 & $3.26 \pm 0.44$ & 6 \\
\hline 21 & $4.59 \pm 0.46$ & 3 & $4.76 \pm 0.62$ & 3 & $3.72 \pm 0.30$ & 5 & $3.28 \pm 0.19$ & 6 \\
\hline
\end{tabular}

SD, standard deviation; SWS, shear wave speed.

the cystic, calcified and necrotic areas, thereby affecting the result $(36,47)$. Furthermore, $\mathrm{SWS}_{\text {mean }}$ achieved the highest diagnostic performance compared with the other measured values.

As a new member of the TM4SF family, the NET- 1 gene was identified to be overexpressed in certain tumors, including HCC, gastric cancer, colorectal adenocarcinoma and skin squamous cell carcinoma $(21,48)$. The present study used siRNA to inhibit NET-1 gene expression in a SMMC-7721 xenograft model; each group was treated four times. Subsequently, the level of NET-1 protein in the two treated groups was decreased compared with that in the control groups. The tumor growth curve demonstrated that in the NET-1 siRNA group, the maximum tumor diameter was observed post-treatment; it was significantly decreased compared with that without treatment, additionally illustrating that the overexpression of NET-1 in HCC was involved in cancer cell proliferation (35). NET-1 siRNA-conjugated TNBs, with an average size of $593 \mathrm{~nm}$, were produced using a membrane hydration combined with mechanical oscillation method. Due to the binding of NET-1 siRNA to TNBs, a statistically significant difference in the level of NET-1 protein was observed between the Lipo2000 and TNBs-siRNA groups. In addition, the tumor growth curve demonstrated a maximum diameter of tumor in the TNBs-siRNA group that was significantly decreased compared with that of the Lipo2000 group. However, the difference in the survival time between the two treated groups was small and did not reach statistical significance. These results may be ascribed to the short observation time (60 days). Therefore, additional studies should investigate the delivery system of the nanobubbles at different exposure conditions and concentrations of siRNA, in order to maximize the gene transfection efficiency for tumor therapy in vivo.

Furthermore, one of the major concerns associated the use of these enhancers in clinical studies is the safety of the therapeutic system (38). Non-viral vectors are being increasingly used for gene therapy instead of viral vectors, owing to the concerns about the potential induction of immune responses against viral proteins, endogenous virus recombination and oncogenic effects (49). However, the conventional delivery methods of the non-viral vectors including liposomes and polymeric systems are less than satisfactory, due to the lack of tissue specificity and potential toxicity (50). In the present study, it was identified that the UTMD delivery method exhibited potential in improving gene transfection efficiency. The toxicity of the nanobubbles and the ultrasound radiation have also raised crucial safety issues in clinical studies (38). Therefore, liver and kidney samples were collected from each group of nude mice, and $H \& E$ staining was performed to evaluate the safety of the treatment. In the control groups, malignant pathology was identified in liver samples but not kidney samples, which was uncommon in a previous study (38). This observation may be associated with the highly aggressive and hepatogenic properties of the SMMC-7721 cell line (51). Also, no marked pathological changes were observed in the kidney samples of the TNBs-siRNA group, which was in agreement with a previous study (38).

Nevertheless, the present study had certain limitations. Firstly, the histological development and tumor elasticity 

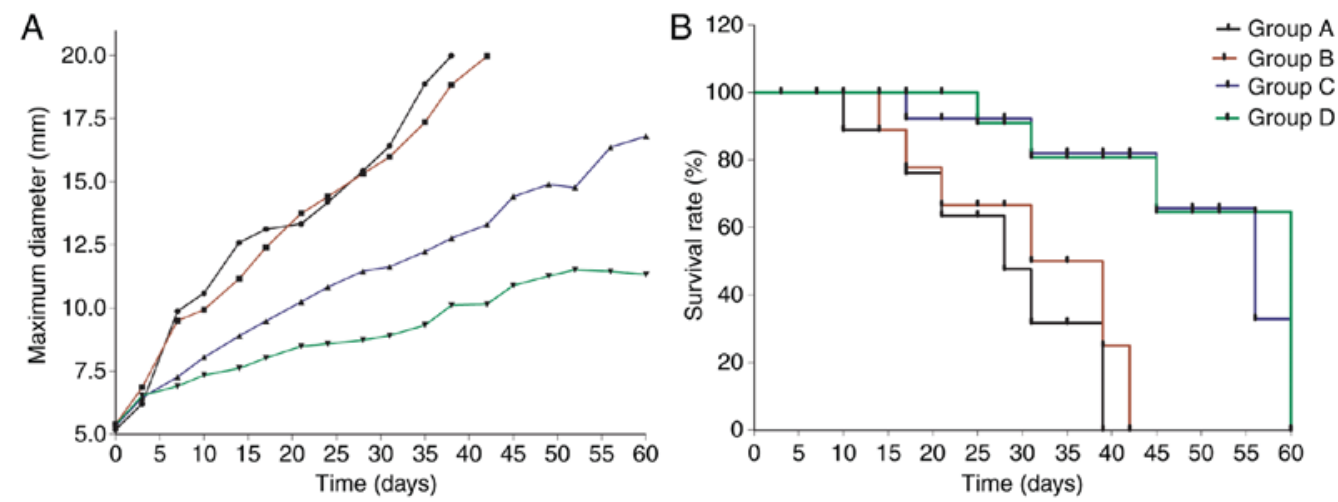

Figure 5. Tumor growth and survival rate of mice. (A) Maximum diameter of tumors in nude mice, and (B) survival rate in the four groups. The tumor size grew rapidly at the injection site during the initial $1-2$ weeks, then the growth slowed as the tumor mass stiffened. Subsequent to treatment, the tumor size in groups $\mathrm{C}$ and $\mathrm{D}$ increased slowly and the median survival time was significantly increased compared with the other two groups.
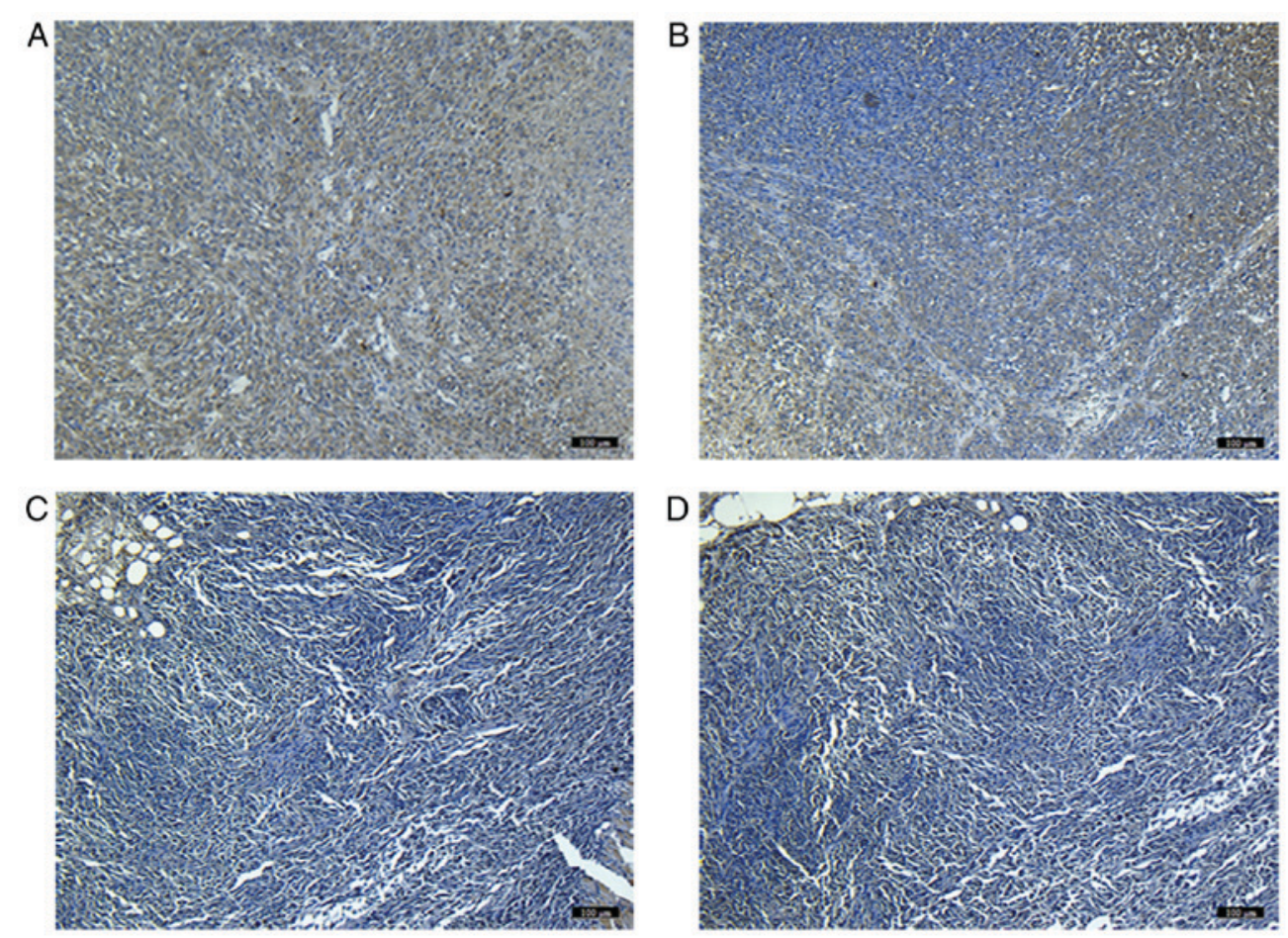

Figure 6. Immunohistochemistry staining. (A) Blank group, (B) TNBs + negative control RNA group, (C) Lipo2000 + siRNA group and (D) TNBs-siRNA group, all at magnification, x100 (scale bar, $100 \mu \mathrm{m}$ ). No statistical difference was observed in the level of NET-1 protein between (A) and (B). The NET-1 expression was significantly decreased in the TNBs group as compared with the blank control $(\mathrm{P}<0.01)$. The level of NET-1 protein in the TNBs group was significantly decreased compared with the Lipo2000 group ( $<<0.05$ ). NET-1, Neuroepithelial cell-transforming gene 1 protein; siRNA, small interfering RNA; Lipo2000, Lipofectamine ${ }^{\circledR} 2000$; TNBs, targeted nanobubbles.
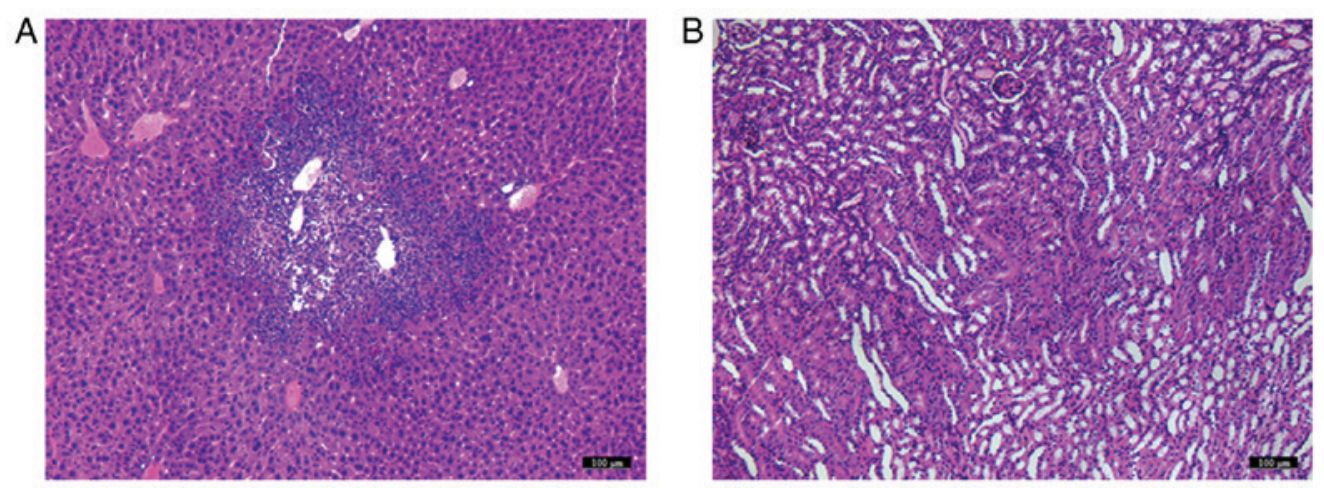

Figure 7. Hematoxylin and eosin staining. (A) Liver and (B) kidney samples at magnification, x100 (scale bar, $100 \mu$ m). Malignant pathology was observed in a liver sample from the blank control group (day 38). (B) Image of kidney sample from a nude mice-bearing tumor in TNBs (targeted nanobubbles)-small interfering RNA group, in which no marked damage was indicated. 
during tumor progression was not compared. Therefore, an association between SWS and pathological processes of the tumors was not able to be established. However, this was not the aim of the present study, as previous studies have demonstrated that the difference in the stiffness is associated with tissue reorganization, particularly fibrosis and necrosis $(2,47,52)$. Secondly, the results of these experiments are not directly applicable to human liver cancer tissues: The present tumor model was implanted under the skin of the nude mice. Although central necrosis is not commonly identified in small human liver cancer, it was observed in the present model as the blood supply to the skin tissue may be decreased compared with that in human liver tissue (53).

In summary, the NET-1 siRNA-TNBs synthesized in the present study were effective in vivo, including the nanoscale size, low toxicity and high transfection efficiency in the tumor. The present study not only described an effective gene vehicle, but also identified a novel elastography technique for investigation of the stiffness of HCC tissues.

\section{Acknowledgements}

Not applicable.

\section{Funding}

The present study was supported by the National Natural Science Foundation of China (grant nos. 81571682 and 81371568), and the Fundamental Research for the Provincial Universities (grant no. 2017LCZX91).

\section{Availability of data and materials}

The datasets used and/or analyzed during the current study are available from the corresponding author on reasonable request.

\section{Authors' contributions}

BW prepared and characterized of NET-1 small interfering RNA (siRNA)-conjugated targeted nanobubbles. HS was in charge of the xenograft model and gene transfection. XL performed VTIQ measurement and was a major contributor in writing the manuscript. XH contributed to the analysis of the VTIQ measurement. HJ and YS analyzed and interpreted IHC and toxicity test. YS was in charge of revising the article. WC contributed to study design. All authors read and approved the final manuscript.

\section{Ethics approval and consent to participate}

All animal experiments were approved by the Institutional Animal Care and Use Committee of Harbin Medical University Cancer Hospital (Harbin, China). All procedures were performed according to the Guidelines for Tumor Induction in Mice and Rats (updated May 2013).

\section{Patient consent for publication}

Not applicable.

\section{Competing interests}

The authors declare that they have no competing interests.

\section{References}

1. Yao MH, Wu R, Xu G, Zhao LX, Liu H, Pu H and Fang Y: A novel two-dimensional quantitative shear wave elastography to make differential diagnosis of breast lesions: Comprehensive evaluation and influencing factors. Clin Hemorheol Microcirc 64: 223-233, 2016

2. Özkan MB, Bilgici MC, Eren E, Caltepe G, Yilmaz G, Kara C and Gun S: Role of point shear wave elastography in the determination of the severity of fibrosis in pediatric liver diseases with pathologic correlations. J Ultrasound Med 36: 2337-2344, 2017.

3. Tozaki M, Saito M, Benson J, Fan L and Isobe S: Shear wave velocity measurements for differential diagnosis of solid breast masses: A comparison between virtual touch quantification and virtual touch IQ. Ultrasound Med Biol 39: 2233-2245, 2013.

4. Ianculescu V, Ciolovan LM, Dunant A, Vielh P, Mazouni C, Delaloge S, Dromain C, Blidaru A and Balleyguier C: Added value of virtual touch IQ shear wave elastography in the ultrasound assessment of breast lesions. Eur J Radiol 83: 773-777, 2014.

5. Ben Z, Gao S, Wu W, Chen S, Fu S, Zhang J and Chen Y: Clinical value of the VTIQ technology in the differential diagnosis of superficially enlarged lymph nodes. Acta Radiol 59: 836-844, 2018.

6. Yeh CC, Horng $\mathrm{HC}$ and Wang PH: Acoustic radiation force imaging (ARFI): A new powerful tool of ultrasound. J Chin Med Assoc 80: 681-682, 2017.

7. Zhang Y, Luo L and Luo Q: Identification of benign and malignant endometrial cancer with transvaginal ultrasonography combined with elastography and tissue hardness analysis. J Biol Regul Homeost Agents 29: 905-912, 2015.

8. Seguin J, Mignet N, Latorre Ossa H, Tanter M and Gennisson JL: Evaluation of antivascular combretastatin A4 P efficacy using supersonic shear imaging technique of ectopic colon carcinoma CT26. Ultrasound Med Biol 43: 2352-2361, 2017.

9. Torre LA, Bray F, Siegel RL, Ferlay J, Lortet-Tieulent J and Jemal A: Global cancer statistics, 2012. CA Cancer J Clin 65: 87-108, 2015.

10. Sherman M: Hepatocellular carcinoma: Epidemiology, surveillance, and diagnosis. Semin Liver Dis 30: 3-16, 2010.

11. Le Grazie M, Biagini MR, Tarocchi M, Polvani S and Galli A: Chemotherapy for hepatocellular carcinoma: The present and the future. World J Hepatol 9: 907-920, 2017.

12. van't Veer LJ and Bernards R: Enabling personalized cancer medicine through analysis of gene-expression patterns. Nature 452: 564-570, 2008.

13. Xue Y, Yang G, Wang C, Li X and Du G: Effects of shRNA-mediated SOX9 inhibition on cell proliferation and apoptosis in human HCC cell line Hep3B mediated by ultrasound-targeted microbubble destruction (UTMD). Cell Biochem Biophys 73: 553-558, 2015.

14. Avila MA, Berasain C, Sangro B and Prieto J: New therapies for hepatocellular carcinoma. Oncogene 25: 3866-3884, 2006.

15. Gomes-da-Silva LC,Fonseca NA, Moura V,Pedroso de Lima MC, Simões S and Moreira JN: Lipid-based nanoparticles for siRNA delivery in cancer therapy: Paradigms and challenges. Acc Chem Res 45: 1163-1171, 2012 .

16. Wu YY, Chen L, Wang GL, Zhang YX, Zhou JM, He S, Qin J and Zhu YY: Inhibition of hepatocellular carcinoma growth and angiogenesis by dual silencing of NET-1 and VEGF. J Mol Histol 44: 433-445, 2013.

17. Wang GL, Chen L, Wei YZ, Zhou JM, Wu YY, Zhang YX, Qin J and Zhu YY: The effect of NET-1 on the proliferation, migration and endocytosis of the SMMC-7721 HCC cell line. Oncol Rep 27: 1944-1952, 2012.

18. Qiu DM, Wang GL, Chen L, Xu YY, He S, Cao XL, Qin J, Zhou JM, Zhang YX and E Q: The expression of beclin-1, an autophagic gene, in hepatocellular carcinoma associated with clinical pathological and prognostic significance. BMC Cancer 14: 327, 2014.

19. Ye K, Wang Z, Zhang G and Liang S: Prognostic significance of neuroepithelial transforming protein 1 in hepatocellular carcinoma. J Invest Surg 23: 163-169, 2010. 
20. Chen L, Wang Z, Zhan X, Li DC, Zhu YY and Zhu J: Association of NET-1 gene expression with human hepatocellular carcinoma. Int J Surg Pathol 15: 346-353, 2007.

21. Li T, Xue Y, Wang G, Gu T, Li Y, Zhu YY and Chen L: Multi-target siRNA: Therapeutic strategy for hepatocellular carcinoma. J Cancer 7: 1317-1327, 2016.

22. Han X, Cheng W, Jing H, Zhang JW and Tang LL: Neuroepithelial transforming protein 1 short interfering RNA-mediated gene silencing with microbubble and ultrasound exposure inhibits the proliferation of hepatic carcinoma cells in vitro. J Ultrasound Med 31: 853-861, 2012.

23. He S, Wei YZ, Wang GL, Xu YY, Zhou JM, Zhang YX and Chen L: Study of RNA interference targeting NET-1 combination with sorafenib for hepatocellular carcinoma therapy in vitro and in vivo. Gastroenterol Res Pract 2013: 685150, 2013.

24. Tsuchiya N, Sawada Y, Endo I, Saito K, Uemura Y and Nakatsura T: Biomarkers for the early diagnosis of hepatocellular carcinoma. World J Gastroenterol 21: 10573-10583, 2015.

25. Jing JS, Ye W, Jiang YK, Ma J, Zhu MQ, Ma JM, Zhou H, Yu LQ, Yang YF and Wang SC: The value of GPC3 and GP73 in clinical diagnosis of hepatocellular carcinoma. Clin Lab 63: 1903-1909, 2017.

26. Montalbano M, Rastellini C, McGuire JT, Prajapati J, Shirafkan A, Vento R and Cicalese L: Role of Glypican-3 in the growth, migration and invasion of primary hepatocytes isolated from patients with hepatocellular carcinoma. Cell Oncol 41: 169-184, 2018.

27. Tsuchiya N, Yoshikawa T, Fujinami N, Saito K, Mizuno S, Sawada Y, Endo I and Nakatsura T: Immunological efficacy of glypican-3 peptide vaccine in patients with advanced hepatocellular carcinoma. Oncoimmunology 6: e1346764, 2017.

28. Chen JJ, Xie CM, Wang CR, Wan Y, Dong ZN, Li M and Xu WW: Development of a time-resolved fluorescence immunoassay for the diagnosis of hepatocellular carcinoma based on the detection of glypican-3. J Fluoresc 27: 1479-1485, 2017.

29. Li M, Zhang W, Wang B, Gao Y, Song Z and Zheng QC: Ligand-based targeted therapy: A novel strategy for hepatocellular carcinoma. Int J Nanomedicine 11: 5645-5669, 2016.

30. Kievit FM and Zhang M: Cancer nanotheranostics: Improving imaging and therapy by targeted delivery across biological barriers. Adv Mater 23: H217-H247, 2011.

31. Yang J, Hendricks W, Liu G, McCaffery JM, Kinzler KW, Huso DL, Vogelstein B and Zhou S: A nanoparticle formulation that selectively transfects metastatic tumors in mice. Proc Natl Acad Sci USA 110: 14717-14722, 2013.

32. Eggen S, Fagerland SM, Mørch Ý, Hansen R, Søvik K, Berg S, Furu H, Bøhn AD, Lilledahl MB, Angelsen A, et al: Ultrasound-enhanced drug delivery in prostate cancer xenografts by nanoparticles stabilizing microbubbles. J Control Release 187: 39-49, 2014.

33. Juffermans LJ, Meijering BD, Henning RH and Deelman LE: Ultrasound and microbubble-targeted delivery of small interfering RNA into primary endothelial cells is more effective than delivery of plasmid DNA. Ultrasound Med Biol 40: 532-540, 2014.

34. Meng M, Gao J, Wu C, Zhou X, Zang X, Lin X, Liu H, Wang C, Su H, Liu K, et al: Doxorubicin nanobubble for combining ultrasonography and targeted chemotherapy of rabbit with VX2 liver tumor. Tumour Biol 37: 8673-8680, 2016.

35. Wu B, Qiao Q, Han X, Jing H, Zhang H, Liang $\mathrm{H}$ and Cheng W: Targeted nanobubbles in low-frequency ultrasound-mediated gene transfection and growth inhibition of hepatocellular carcinoma cells. Tumour Biol 37: 12113-12121, 2016.

36. Yang YP, Xu XH, Bo XW, Liu BJ, Guo LH, Xu JM, Sun LP and Xu HX: Comparison of virtual touch tissue imaging \& quantification (VTIQ) and virtual touch tissue quantification (VTQ) for diagnosis of thyroid nodules. Clin Hemorheol Microcirc 65: 137-149, 2017.

37. He YP, Xu HX, Li XL, Li DD, Bo XW, Zhao CK, Liu BJ, Wang D and Xu HX: Comparison of virtual touch tissue imaging \& quantification (VTIQ) and Toshiba shear wave elastography (T-SWE) in diagnosis of thyroid nodules: Initial experience. Clin Hemorheol Microc 66: 15-26, 2017.

38. Park DH, Jung BK, Lee YS, Jang JY, Kim MK, Lee JK, Park H, Seo J and Kim CW: Evaluation of in vivo antitumor effects of ANT2 shRNA delivered using PEI and ultrasound with microbubbles. Gene Ther 22: 325-332, 2015.
39. Lucero HA, Patterson S, Matsuura S and Ravid K: Quantitative histological image analyses of reticulin fibers in a myelofibrotic mouse. J Biol Methods 3: e60, 2016.

40. Peng H, Birkett GR and Nguyen AV: Progress on the surface nanobubble story: What is in the bubble? Why does it exist? Adv Colloid Interface Sci 222: 573-580, 2015.

41. Kapetas P, Pinker-Domenig K, Woitek R, Clauser P, Bernathova M, Spick C, Helbich T and Baltzer PA: Clinical application of acoustic radiation force impulse imaging with Virtual Touch IQ in breast ultrasound: Diagnostic performance and reproducibility of a new technique. Acta Radiol 58: 140-147, 2017.

42. Chamming's F, Latorre-Ossa H, Le Frère-Belda MA, Fitoussi V, Quibel T, Assayag F, Marangoni E, Autret G, Balvay D, Pidial L, et al: Shear wave elastography of tumour growth in a human breast cancer model with pathological correlation. Eur Radiol 23: 2079-2086, 2013.

43. Li J, Wu Y, Schimmel N, Al-Ameen MA and Ghosh G: Breast cancer cells mechanosensing in engineered matrices: Correlation with aggressive phenotype. J Mech Behav Biomed Mater 61: 208-220, 2016.

44. Zhou H, Zhou XL, Xu HX, Li DD, Liu BJ, Zhang YF, Xu JM, Bo XW, Li XL, Guo LH and Qu S: Virtual touch tissue imaging and quantification in the evaluation of thyroid nodules. J Ultrasound Med 36: 251-260, 2017.

45. Chamming's F, Le-Frère-Belda MA, Latorre-Ossa H, Fitoussi V, Redheuil A, Assayag F, Pidial L, Gennisson JL, Tanter M, Cuénod CA and Fournier LS: Supersonic shear wave elastography of response to anti-cancer therapy in a xenograft tumor model. Ultrasound Med Biol 42: 924-930, 2016.

46. Kasai Y, Moriyasu F, Saito K, Hara T, Kobayashi Y, Nakamura I and Sugimoto K: Value of shear wave elastography for predicting hepatocellular carcinoma and esophagogastric varices in patients with chronic liver disease. J Med Ultrason 42: 349-355, 2015.

47. Sun CY, Lei KR, Liu BJ, Bo XW, Li XL, He YP, Wang D, Ren WW, Zhao CK and Xu HX: Virtual touch tissue imaging and quantification (VTIQ) in the evaluation of thyroid nodules: The associated factors leading to misdiagnosis. Sci Rep 7: 41958, 2017.

48. Ji ZJ, Wang JL and Chen L: Inhibition of skin squamous cell carcinoma proliferation and promote apoptosis by dual silencing of NET-1 and survivin. Oncol Rep 34: 811-822, 2015.

49. Chen ZY, Liang K, Lin Y and Yang F: Study of the UTMD-based delivery system to induce cervical cancer cell apoptosis and inhibit proliferation with shRNA targeting Survivin. Int J Mol Sci 14: 1763-1777, 2013.

50. Lee H, Lytton-Jean AK, Chen Y, Love KT, Park AI, Karagiannis ED, Sehgal A, Querbes W, Zurenko CS, Jayaraman M, et al: Molecularly self-assembled nucleic acid nanoparticles for targeted in vivo siRNA delivery. Nat Nanotechnol 7: 389-393, 2012.

51. Xu B, Yao M, Gu W, Yan M, Liu L and Zhang J: Establishment and biological characteristics of mouse models mimicking postoperative human carcinoma metastasis. Nan Fang Yi Ke Da Xue Xue Bao 27: 1009-1011, 2007 (In Chinese).

52. Elyas E, Papaevangelou E, Alles EJ, Erler JT, Cox TR, Robinson SP and Bamber JC: Correlation of ultrasound shear wave elastography with pathological analysis in a xenografic tumour model. Sci Rep 7: 165, 2017.

53. von Ardenne M: Differences in induction of the cellular switch mechanism of blood microcirculation in various organs and tissues of the human body. Z Alternsforsch 40: 357-368, 1985 (In German).

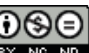

This work is licensed under a Creative Commons Attribution-NonCommercial-NoDerivatives 4.0 International (CC BY-NC-ND 4.0) License. 